\title{
Teaching GLM Concepts: Explicating the Connections
}

\author{
Susan Troncoso Skidmore \\ Sam Houston State University
}

\begin{abstract}
The purpose of the present paper is to encourage textbook authors, quantitative instructors, curriculum writers, and software developers to move away from the use of isolated apparently disconnected analyses and instead move towards the use of the general linear model as a foundational framework for graduate level statistics training. It is argued that an understanding of modeling, simple linear equations, and commonly used analogous statistical terms will facilitate students understanding of frequently used parametric analyses. Additionally, this holistic approach will equip students with the necessary preparatory skills to understand newer analytical approaches. Three heuristic examples are provided.
\end{abstract}

Keywords: General Linear Model, quantitative training, statistical modeling

Although researchers have clearly demonstrated the linkages among parametric analyses within the General Linear Model (GLM) by showing that structural equation modeling is the more general case of canonical correlation analysis (Bagozzi, Fornell, \& Larcker, 1981; Fan, 1997; Graham, 2008) and that canonical correlation analysis in turn subsumes classical statistical analyses (Knapp, 1978; Thompson, 1984), instructional practices have not changed appreciably. Typical undergraduate psychology introductory statistics course sequences include classical statistical analyses (e.g., $t$-test, ANOVA, regression). These analyses are often introduced as isolated analyses unique in name and purpose with little to no emphasis on effect sizes, confidence intervals, and GLM approaches (Chartier \& Faulkner, 2008; Friedrich, Buday, \& Kerr, 2000). At the doctoral level, topics covered in methodological courses serve to equip students with the fundamental competencies necessary to successfully engage in and contribute to the field. Yet there is a limited amount of methodological training ( $M d n=1.6$ years; Aiken, West, \& Millsap, 2008) required in doctoral curricula, so authors of statistics texts, methodological instructors, and course designers would be wise to focus on general foundational frameworks which maximize students ability to transfer their learning experiences to new analytical situations. Further by explicitly recognizing the unifying structure that underlies all parametric analyses, a strong advanced organizer for students to more powerfully internalize that parametric analyses are not individual disconnected analyses can be promoted. 
Indeed, instead of teaching discrete univariate (e.g., $t$-test, ANOVA, correlation, and regression) and multivariate examples (e.g., discriminant analysis, MANOVA, principal components analysis, canonical correlation analysis, and structural equation modeling) of commonly used parametric statistics, instructors could instead focus on the fact that these analyses have a common framework. This framework, at its simplest, is a mathematical procedure that results in the creation of a composite variable. The composite variable scores are calculated as a linear function of one or more observed variables. The estimation of the composite scores is maximized by the use of weights applied to the observed variable(s). The quality of the model is contingent upon the extent to which the calculated composite variable accurately represents the observed outcome variable of interest. A variance accounted for effect size, such as $R^{2}$, quantifies the extent to which the observed variables are able to explain or predict the variability observed in the outcome variable of interest. Axiomatically, effect sizes such as $R^{2}$ provide an estimate of model fit.

In positing that the understanding of GLM would facilitate the acquisition of fundamental methodological competencies, it is important to first consider the purpose of doctoral training in statistics. Do all doctoral students in psychology really need to be prepared to engage in and contribute to the field? After all, fundamental competencies for future quantitative psychologists are inherently different from those of future clinicians. Or are they? Could it be that a firm foundation in the basic principles of the GLM is the springboard from which sound statistical reasoning could emerge? According to Wilks (1951), H. G. Wells claimed that "statistical thinking will one day be as necessary for efficient citizenship as the ability to read and write" (p. 40). In our present information satiated society, it seems that the future that Wells envisioned has become a reality. Certainly then, sound statistical reasoning is a realistic expectation of doctoral students. Commentary by Aiken, West, and Millsap (2009) regarding quantitative training, contended that "the same solid foundation [in methodology] will also serve the acquisition later in life of diverse methodologies needed to support basic as well as applied research in a wide range of work settings" (Aiken, West, \& Millsap, 2009, p. 52). Although Aiken et al. were not specifically referring to the GLM, the purpose of the present paper does argue that the GLM could and should serve as a foundational framework in graduate level statistics courses.

\section{Quantitative Training in Psychology}

Aiken, West, \& Millsap (2009) relay the necessity of sound quantitative and methodological training noting that "[a] Ph.D. psychologist should be able to evaluate and generate new scientific knowledge in psychology" 
(p. 51). Similarly, Rossen and Oakland (2008) noted that "graduate preparation in research methods is needed to help ensure that the next generation of psychologists is prepared to consume and engage in research" (p. 42). Espousing such a position about quantitative and methodological training, it follows that poor training negatively impacts "the progress of substantive areas" (Aiken, West, Sechrest, \& Reno, 1990, p. 731). As such, quantitative training becomes everyone's concern.

An understanding of the topical coverage and amount of time allotted to quantitative training can provide an indication of the quality of training received. In Rossen and Oakland's (2008) survey of graduate professional programs, specifically APA accredited programs, the authors provided that 96\% of the responding programs required an introduction to statistics (Rossen \& Oakland, 2008), which is similar to Aiken, West, and Millsap's (2008) estimates from their survey of Ph.D. programs in psychology across the United States and Canada. Nonetheless, researchers have noted the limited time ( $M d n=1.6$ years) devoted to quantitative training in Ph.D. programs in psychology (Aiken, West, \& Millsap, 2008).

Perhaps even more telling than the number of years spent in quantitative training is the content of the courses. The introductory quantitative course sequence was found to be primarily centered on ANOVA although an increased focus on regression was noted (Aiken, West, \& Millsap, 2008). This content appears to mirror the generally downward trend in the use of ANOVA and generally upward trend in the use of regression in psychology journals from 1948-2001 (Skidmore \& Thompson, 2010). Indeed, Silverman (1987) has noted that "journals both create and mirror their fields" (p.40). Apparently quantitative and methodological training is reflected in the field as well.

Other researchers examined psychotherapy related fields and the impact of graduate students' research training environment (RTE). Posited to exist in the RTE are 10 components within two higher order factors (interpersonal and instructional) thought to influence research attitudes, efficacy, and productivity (Gelso, Baumann, Chui, \& Savela, 2013). Of these 10 components, the instructional factor component, focused on effective and relevant statistics instruction, is particularly relevant to the present discussion. Gelso (2006) noted that students' first experiences with research, often in introductory statistics courses, could be "psychonoxious" (p. 8). Although GLM was not specifically considered, Gelso (2006) noted "Statistics courses that are insensitively and ineffectively taught can traumatize students and deeply affect research interest. The most influential RTEs actively seek to assure that quantitative instruction fits the level and needs of budding applied researchers" (p. 13). An explicit framework, such as GLM, that undergirds other more complex analyses could offer a useful scaffold for developing researchers. 
Another approach in understanding the content coverage in introductory graduate level statistics courses is to examine the course descriptions for those introductory courses. The office of the University Registrar at Stanford University notes that course descriptions are "about the subject matter, approach, breadth, and applicability of the course" and notes that "students need to be able to tell prospective universities and employers what the course was about in a short, content-filled way" (n. a., 2014). Admittedly, course descriptions are succinct typically but they do offer a glimpse into the course content. Further, unlike surveys where individuals are responsible for reporting what courses are about, course descriptions are a symbol of the institutionalized expectations regarding the course. In addition, course descriptions are publicly available and can be tied directly to specific degree plans, which are also publicly available.

Using the Carnegie Classification system, 4-year or above public universities classified as having very high research activity were identified. Degree plans in psychology programs in each of the universities were located. Degree plans were searched for the lowest level quantitative course on the degree plan. Displayed in Table 1 are the results of the content analysis of the course descriptions.

The most salient descriptor in introductory graduate level statistics courses was hypothesis testing (54.8\%), variously described as hypothesis testing, significance tests, tests of significance, etc. The next most salient descriptor, noted in almost half of the course descriptions, was ANOVA. Present in roughly equal proportions was experimental design (28.8\%), and analysis, statistical software, and regression, with $27.4 \%$ each. The general linear model was noted in only six courses.

\section{Foundational Knowledge}

Given that (a) a limited amount of time is available in the curriculum for quantitative training (Aiken, West, \& Millsap, 2008), (b) parametric analyses subsumed under the GLM such as ANOVA, correlation, regression, are the most commonly used analyses (Skidmore \& Thompson, 2010), and (c) these classical methods are "still best for many questions, and ... are the basis for the newer approaches" (Wickens, 2004, p.1) then it only makes sense to provide students with a strong foundational structure in the GLM within the introductory course sequence.

Because several of the courses reviewed in the present study noted GLM in the course description, a search for syllabi for those courses ostensibly provides more details about what a course structured with GLM principles in mind might look like. Of the six courses that included the GLM in the course description only one provided an accessible syllabus

online. The course, Statistical Methods in Psychological Research, was 
Table 1

Frequencies and Percentages of Descriptors Used in Course Descriptions for Introductory Level Graduate Statistics Courses

\begin{tabular}{lcc}
\hline Descriptor & Count & $\%$ \\
\hline Hypothesis testing & 40 & 54.8 \\
ANOVA & 35 & 47.9 \\
Experimental design & 21 & 28.8 \\
Analysis & 20 & 27.4 \\
Statistical software & 20 & 27.4 \\
Regression & 20 & 27.4 \\
Correlation & 16 & 21.9 \\
Interpretation and presentation & 13 & 17.8 \\
Center, shape, spread & 11 & 15.1 \\
Nonparametric techniques & 11 & 15.1 \\
Description & 10 & 13.7 \\
$t$-test & 7 & 9.6 \\
Interval estimation & 7 & 9.6 \\
General Linear Model & 6 & 8.2 \\
Data exploration techniques & 4 & 5.5 \\
Effect sizes & 3 & 4.1 \\
\hline
\end{tabular}

Note. Programs included clinical, counseling, developmental, educational, quantitative, school, and social psychology.

taught by Professor Aurelio José Figueredo from the University of Arizona. Figueredo (2011) noted the following as the goal of the course:

to develop the requisite level of critical thinking and philosophical background for conducting valid quantitative research rather than a "cookbook" familiarity with traditional statistical procedures. This involves a conceptual understanding of the underlying philosophical basis of empirical science as well as of the mathematical foundations and interrelationships of the major statistical models now available [bolding added] p.1.

The emphasis on critical thinking in contrast to surface procedural knowledge of isolated statistical techniques is key to providing a foundation for sound statistical reasoning. An integrated approach is the opposite of the historical approach, where statistical techniques were taught in isolation. Graham commented on the dangers of this disconnected method, stating that when "taught in this manner, procedures can seem overly complex and intimidating to students, who 
lack an overall framework" (Graham, 2008, p. 486). Students equipped with general principles of modeling will have a much easier time understanding and thoughtfully using not only the classical approaches but the newer approaches as well.

\section{Emphasis on Modeling}

As a way to scaffold students' understanding of statistical models, instructors can begin to probe students' understandings and misunderstandings of modeling in general. One important way modeling can be conceptualized is as a representation of reality. A model, however, is not reality. It is often a much simplified version of reality. A model therefore, is always incomplete. Box and Draper's words (1987), "all models are wrong; the practical question is how wrong do they have to be to not be useful," offer a valuable perspective (p. 74).

The black box experiment is a useful tool to help students tangibly understand the modeling process. The black box is literally a rectangular black box with an opening at the top of the box and an opening at the bottom. Students are provided with a graduated cylinder and a container of water. Students are instructed to pour water into the top opening and observe what happens. They are not allowed to open the box or to move it in any way. Students record the amount of water put into the top of the black box and the amount that comes out. The box is designed to where sometimes a large amount of water is put in, and none comes out. Sometimes a small amount of water is put in and a large amount of water comes out. Students often assume that when they begin the experiment, the box is empty, which may or may not be a correct assumption. After several rounds of data collection and discussion with peers, students are asked to sketch a model of what mechanism might be inside the box that produced the observed results. Students present and critique each other's models, noting the utility of each model, and its limitations. The black box experiment has been used in science classrooms and in the professional development of science instructors (Ruebush, Sulikowski, \& North, 2009; Ruebush, Grossman, Miller, North, Schielack, \& Simanek, 2010). A rubric is available to qualify students understanding of models (c.f. Ruebush et. al, 2010).

This activity is a tangible way to discuss foundational terms such as, systematic data collection, validity, reliability, and the presence of multiple plausible models. Another strength of this approach is the fact that students will never know what mechanism is within the black box. Because the mechanism is never revealed to them, fruitful discussions unfold about the inability to know the true mechanism with certainty even if they believe their models is plausible. As a result, students can begin to shift their thinking from proving their model is correct to providing sufficient 
evidence in support of their conclusions, while recognizing the necessity to acknowledge and test alternative plausible models.

\section{A Simple Heuristic Example}

After helping students more clearly understand the concept of modeling, discussions about mathematical models, and more specifically linear models, can be approached with examples. A simple heuristic example that can be used is to develop a model to understand doctoral students' height. The purpose of this model is to (a) demonstrate explicitly a simple mathematical model and (b) help students explicitly understand terms such as, observed variables, unobserved variables, y, y-hat, error, and weights as well as the basic notation for a linear equation.

To introduce these topics, students are told that their task is to develop a model to estimate doctoral students' height. Each of them is asked to provide their height. Next, students are asked if there is something that could be used to help predict or estimate other doctoral students' height. Undoubtedly someone will respond that the average height would be a fair estimate. This of course allows for multiple "What if?" discussions. What if a really tall (or short) person is in class, would the average still be the best estimate?

Using a spreadsheet a graphical plot of the points the students provided is drawn. See Figure 1. The simple mathematical model with no predictors, $y_{i}=\beta_{0}+\varepsilon_{i}$, or more simply, $\mathrm{Y}=$ intercept + error is introduced. The intercept $\left(\beta_{0}\right)$, in this simple case of no predictors is equivalent to the mean height of the sample. This also provides the opportunity to contrast Y-hat (predicted Y) and Y (observed Y). To demonstrate that the mean height, or predicted height, is the true mathematical center of the data points (i.e., the sum of the error column equals zero), other values different from the mean are subtracted from $\mathrm{Y}$ and result in greater error. Therefore, with no other information to predict height, the mean height, on average, minimizes prediction error. To understand how to calculate the degree of error in the predicted height for the sample, the sum of the squared deviations from the mean $(S O S)$ is calculated by summing the fifth column. From this $S O S$, calculations for the variance (i.e., dividing the $S O S$ by $n-1$ ) and standard deviation (i.e., taking the square root of the variance) are demonstrated.

Next students are encouraged to consider ways to improve the previous model so that a more accurate predicted height could be obtained. More information, in the form of another variable, is introduced by asking students to provide their shoe size for input into the spreadsheet. See Table 2 and Figure 2. The scatterplot populates as each student's values are entered. 


\section{TEACHING GLM}

Figure 1. Heuristic example of a model with no predictors.

\begin{tabular}{lcccc}
\hline Student & $\begin{array}{c}\text { Height } \\
(\text { Y) }\end{array}$ & $\begin{array}{c}\text { Predicted } \\
\text { Height } \\
(\text { Y-hat })\end{array}$ & $\begin{array}{c}\text { Height } \\
\text { Predicted Height } \\
\text { (Error) }\end{array}$ & $\begin{array}{c}\text { (Height- Predicted } \\
\text { Height })^{2}\end{array}$ \\
\hline 1 & 65.5 & 65.5 & 0.0 & 0.0 \\
2 & 64.0 & 65.5 & -1.5 & 2.3 \\
3 & 62.0 & 65.5 & -3.5 & 12.3 \\
4 & 66.5 & 65.5 & 1.0 & 1.0 \\
5 & 66.0 & 65.5 & 0.5 & 0.3 \\
6 & 67.0 & 65.5 & 1.5 & 2.3 \\
7 & 68.0 & 65.5 & 2.5 & 6.3 \\
8 & 63.5 & 65.5 & -2.0 & 4.0 \\
9 & 64.0 & 65.5 & -1.5 & 2.3 \\
10 & 65.0 & 65.5 & -0.5 & 0.3 \\
11 & 65.0 & 65.5 & -0.5 & 0.3 \\
12 & 67.5 & 65.5 & 2.0 & 4.0 \\
13 & 63.0 & 65.5 & -2.5 & 6.3 \\
14 & 67.5 & 65.5 & 2.0 & 4.0 \\
15 & 68.0 & 65.5 & 2.5 & 6.3 \\
\hline
\end{tabular}

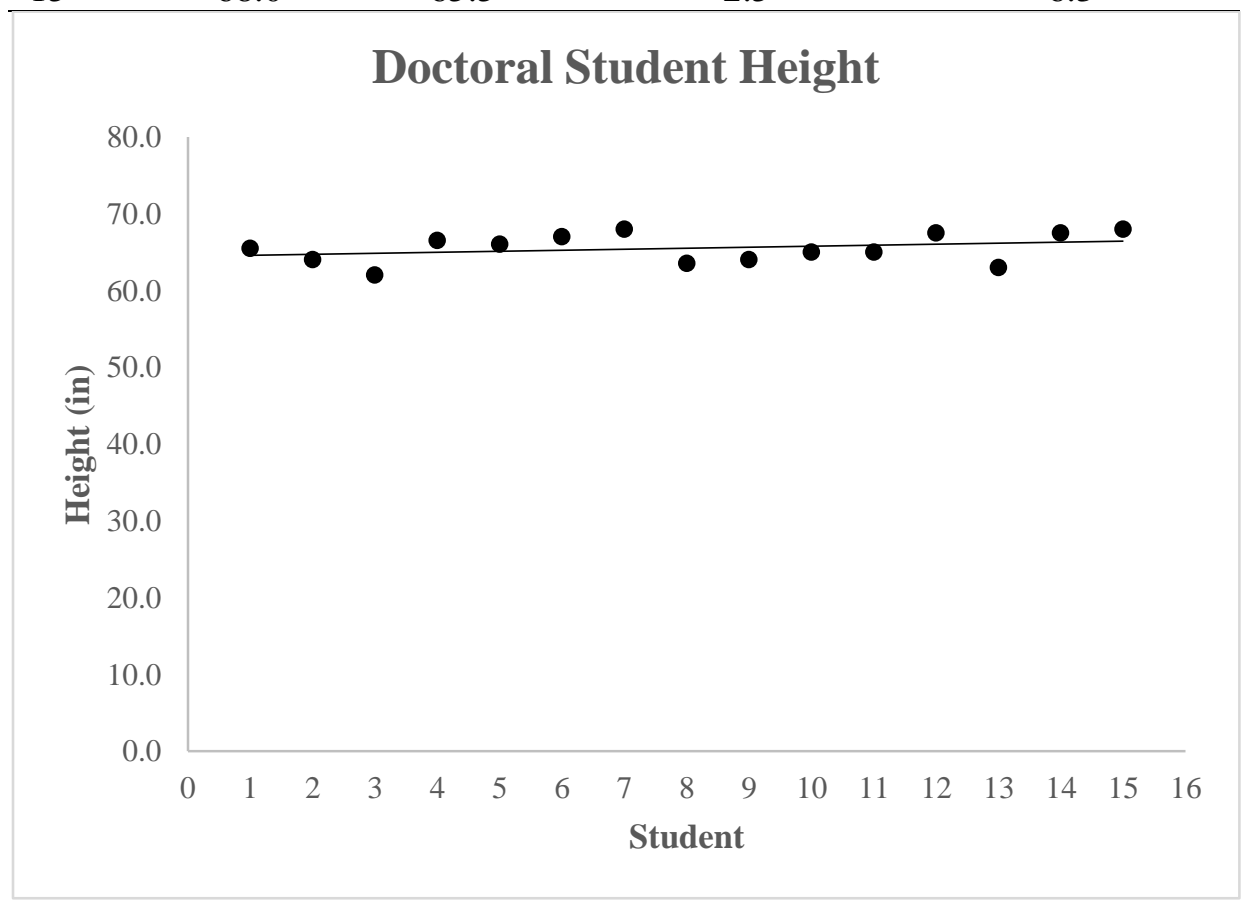




\section{SKIDMORE}

Table 2

Heuristic Example of a Model with a Single Predictor

\begin{tabular}{|c|c|c|c|c|c|c|c|c|c|}
\hline Student & $\begin{array}{l}\text { Shoe } \\
\text { Size } \\
(X)\end{array}$ & $\begin{array}{l}\text { (Shoe Size - } \\
\text { Mean Shoe } \\
\text { Size), } \\
\text { Deviation } \\
\text { X } \\
\end{array}$ & $\begin{array}{l}\text { (Shoe Size - } \\
\text { Mean Shoe } \\
\text { Size) }{ }^{2} \\
\text { Squared } \\
\text { Deviation X }\end{array}$ & $\begin{array}{l}\text { Height } \\
\text { (Y) }\end{array}$ & $\begin{array}{l}\text { (Height - } \\
\text { Mean } \\
\text { Height), } \\
\text { Deviation Y }\end{array}$ & $\begin{array}{c}\text { (Height - } \\
\text { Mean } \\
\text { Height) }{ }^{2} \text {, } \\
\text { Squared } \\
\text { Deviation Y }\end{array}$ & $\begin{array}{l}\text { Deviation } \\
\text { Products }\end{array}$ & $\begin{array}{c}\text { Predicted } \\
\text { Height } \\
\text { (Y-hat) }\end{array}$ & $\begin{array}{c}\text { Height - } \\
\text { Predicted } \\
\text { Height } \\
\text { (Error) }\end{array}$ \\
\hline 1 & 9.5 & 0.3 & 0.1 & 65.5 & 0.0 & 0.0 & 0.0 & 65.7 & -0.2 \\
\hline 2 & 7.5 & -1.7 & 2.9 & 64.0 & -1.5 & 2.3 & 2.6 & 64.2 & -0.2 \\
\hline 3 & 6.5 & -2.7 & $7 \cdot 3$ & 62.0 & -3.5 & 12.3 & 9.5 & 63.4 & -1.4 \\
\hline 4 & 10.0 & 0.8 & 0.6 & 66.5 & 1.0 & 1.0 & 0.8 & 66.1 & 0.4 \\
\hline 5 & 8.0 & -1.2 & 1.4 & 66.0 & 0.5 & 0.3 & -0.6 & 64.6 & 1.4 \\
\hline 6 & 10.0 & 0.8 & 0.6 & 67.0 & 1.5 & 2.3 & 1.2 & 66.1 & 0.9 \\
\hline 7 & 13.0 & 3.8 & 14.4 & 68.0 & 2.5 & 6.3 & 9.5 & 68.4 & -0.4 \\
\hline 8 & 7.0 & -2.2 & 4.8 & 63.5 & -2.0 & 4.0 & 4.4 & 63.8 & -0.3 \\
\hline 9 & 6.5 & -2.7 & $7 \cdot 3$ & 64.0 & -1.5 & 2.3 & 4.1 & 63.4 & 0.6 \\
\hline 10 & 11.0 & 1.8 & 3.2 & 65.0 & -0.5 & 0.3 & -0.9 & 66.9 & -1.9 \\
\hline 11 & 8.5 & -0.7 & 0.5 & 65.0 & -0.5 & 0.3 & 0.4 & 65.0 & 0.0 \\
\hline 12 & 10.5 & 1.3 & 1.7 & 67.5 & 2.0 & 4.0 & 2.6 & 66.5 & 1.0 \\
\hline 13 & 6.0 & -3.2 & 10.2 & 63.0 & -2.5 & 6.3 & 8.0 & 63.1 & -0.1 \\
\hline 14 & 11.5 & 2.3 & $5 \cdot 3$ & 67.5 & 2.0 & 4.0 & 4.6 & 67.2 & 0.3 \\
\hline 15 & 12.5 & 3.3 & 10.9 & 68.0 & 2.5 & 6.3 & 8.3 & 68.0 & 0.0 \\
\hline
\end{tabular}


Next the process of subtracting the variable from the mean, taking the deviation, and squaring the deviation is repeated for Shoe Size (X) and Height (Y). Whereas before the predicted height was constant, the predicted height is variable now. Guided questioning helps students recognize that the variability in the prediction is attributed to the weighting value, or $\beta_{1}$ in the equation, $y_{i}=\beta_{0}+\beta_{1} x_{1}+\varepsilon_{i}$. Students can calculate this weight using the equation, weight of $X=$ sum of the deviation products/ sum of squared deviations of X. They calculate the intercept by using the equation, intercept $=$ mean of $\mathrm{Y}-$ weight $^{*}$ mean of $\mathrm{X}$. The equation for predicted $\mathrm{Y}$ or $\mathrm{Y}$-hat (i.e., the best fit line) is given as the sum of the intercept and the weight multiplied by X. Comparisons to the no predictor model help students see that by adding the variable shoe size, prediction was improved.

Figure 2. Heuristic example of a model with a single predictor.

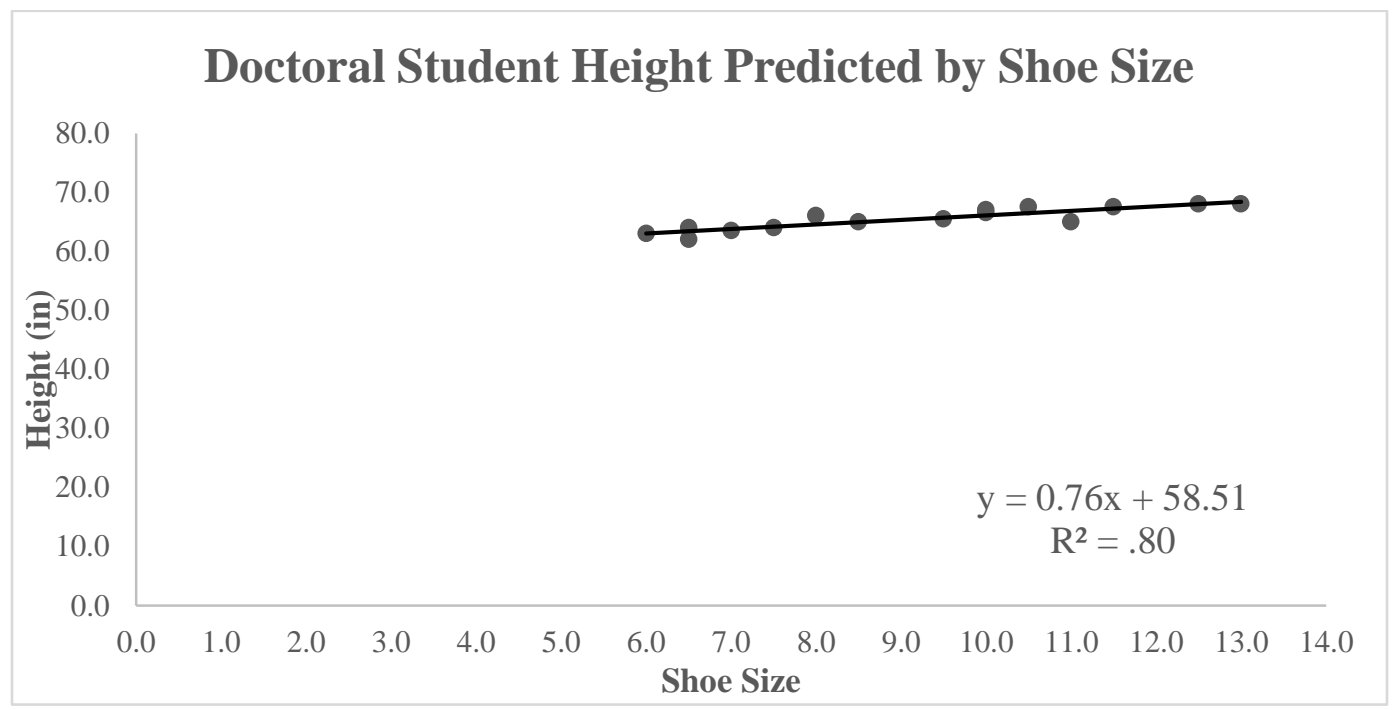

A series of probing questions can help students more thoughtfully consider this linear model. Students can be asked to explain what a perfect model of the relationship between height and shoe size would look like. Another question for consideration is what a useless model of the relationship between height and shoe size would look like. Further, criteria used to assess the "goodness" of a model can be explored. Although this process may take some time, it is a worthwhile investment. If students can begin to understand the simplest of linear models, we can move then from these simple models to more complex models. 


\section{Another Heuristic Example}

The next heuristic example also involves a spreadsheet. In this example students visualize $S O S$ between, $S O S$ within, $S O S$ total, and the variance accounted for effect size, $R^{2}$. Depicted in Figure 3 are 120 squares, 96 of which are shaded. The shaded squares represented the between, or explained, SOS. The unshaded squares represent the within, or unexplained, SOS. Students are asked to find the $S O S$ total by summing the $S O S$ between and $S O S$ within. Next, students are asked to find the proportion of SOS between out of the total SOS. Students then are prompted to understand that this proportion is the proportion of known variability. Put another way, this is the variance that is accounted for and is known as $R^{2}$. Multiple variables can be easily introduced into this visual. The use of multiple variables facilitates discussions about structure coefficients, and standardized and unstandardized coefficients.

Figure 3. Heuristic example for discussing SOS between, SOS within, SOS total, and the variance accounted for effect size, $R^{2}$.

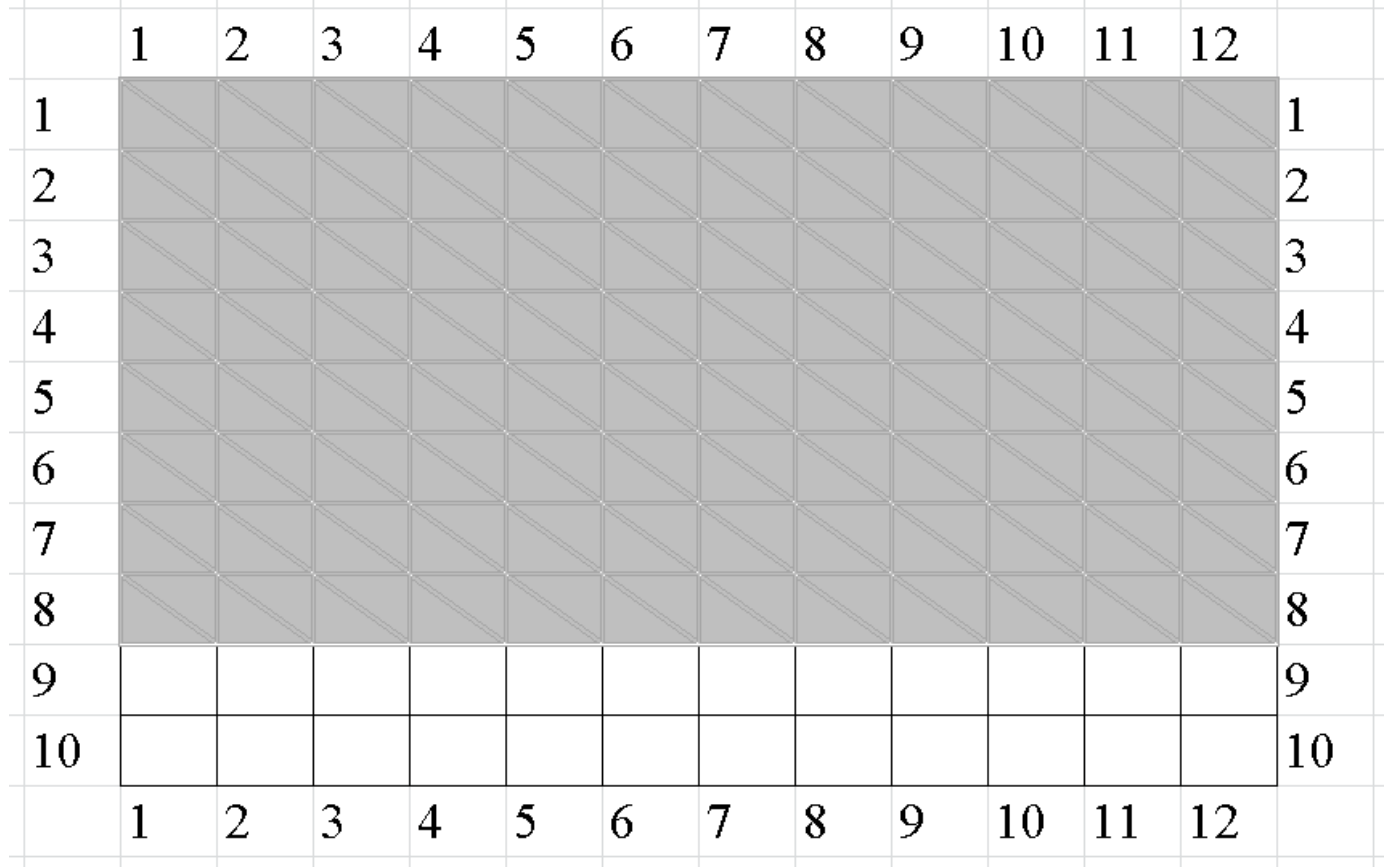

\section{A Final Example Using Software}

Although the previous examples provided an opportunity to visualize the GLM, students likely will not use a worksheet to analyze their data routinely. Instead, students will be using statistical software to run their analyses. In these programs, analyses are referenced typically with traditional names (i.e., regression, ANOVA, etc.). As students become 
accustomed to the software and to the nomenclature used within the software, it becomes all too easy to consider each analysis as a discrete element. Therefore, it is especially important to make explicit the connections to the GLM as observed in the output of statistical programs.

For this example, a dichotomous variable, gender, is added to the data set. To make explicit the connections to the GLM, a separate correlation, $t$-test, ANOVA, and simple regression is run, using gender and height. Provided in Figure 4 on the left is the regression output provided in SPSS ${ }^{\circledR}$. With the printed correlation, $t$-test, and ANOVA output on hand, it is easy to demonstrate how the exact same results provided in the separate analyses (i.e., correlation, $t$-test, and ANOVA) is present in the regression output. On the left side of Figure 4, the correlation output is displayed in the first two tables in the regression output. The pointbiserial correlation between gender and height is statistically significant, $r$ $=.649, r^{2}=.421, p=.004$. The difference between the correlation output $p$ value $(p=.004)$ and that given in the regression output $(p=.009$; final table in the regression output) is due to the default one-tailed test provided in the correlation output, and the default two-tailed test provided in the regression output. Further, it is clear that because this is a simple regression with a single predictor, $R=r$, as provided in the Model Summary output $(R=.649)$. Next, the ANOVA table (fifth table in the regression output) is examined and the square root of the $F$ value is compared to the $t$ statistic provided in the printed $t$-test output. It is of course identical, with an identical $p$ value. Within the regression output the constant is 64.375 , which is the intercept or the mean for the gender type coded as 0 . By adding the b weight (2.411) given in the row titled "gender" to the constant (64.375), the resulting mean for the gender coded as 1 can be computed.

On the right side of Figure 4 is provided the output using the Univariate General Linear Model syntax. The mean of the men and women is provided in the descriptives as well as in the Parameter Estimates table. Here the intercept represents the gender coded as 1, because it has a b weight of $\mathrm{o}$; to get the gender coded as $\mathrm{o}$, you must subtract 2.411 from the intercept $(66.786-2.411=64.375)$. The ANOVA table on the right side is labeled the "Tests of Between-Subject Effects". Indeed, it is easy to see that the same information provided in a traditional ANOVA table, (e.g., $R, R^{2}, F, S O S, d f$ ), is provided in the "Tests of Between-Subject Effects".

Turning now to Unimult ${ }^{\mathrm{TM}}$, the output is provided in Figure 5. The same necessary information provided in SPSS ${ }^{\circledR}$ is provided in Unimult ${ }^{\mathrm{TM}}$. The $r$, equivalent to $R$ in simple regression, and therefore the $r^{2}$ (and $R^{2}$ ) can be calculated $\left(.65^{2}=.42\right)$. The $F$ ratio is also provided, and therefore, the $t$ can be calculated by taking the square root of the $F$. The mean of the men (66.79) and the women (64.38) and the grand mean (65.50) is 


\section{SKIDMORE}

Figure 4. Regression and Univariate General Linear Model Output Comparisons in SPSS ${ }^{\circledR}$

REGRESSION

TDESCRIPTIVES MEAN STDDEV CORR SIG N

/STATISTICS COEFF OUTS CI (95) R ANOVA

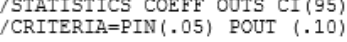

/NOORIGIN

DEPENDENT height

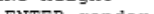

\section{Regression}

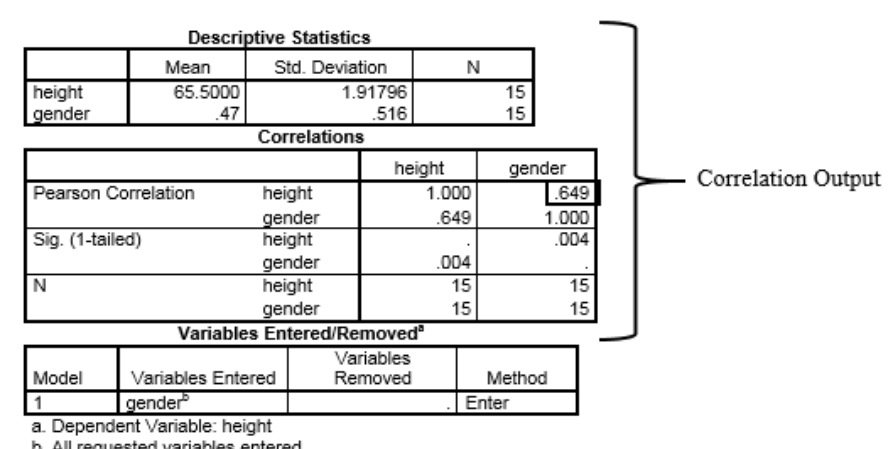

a. Dependent Variable: height
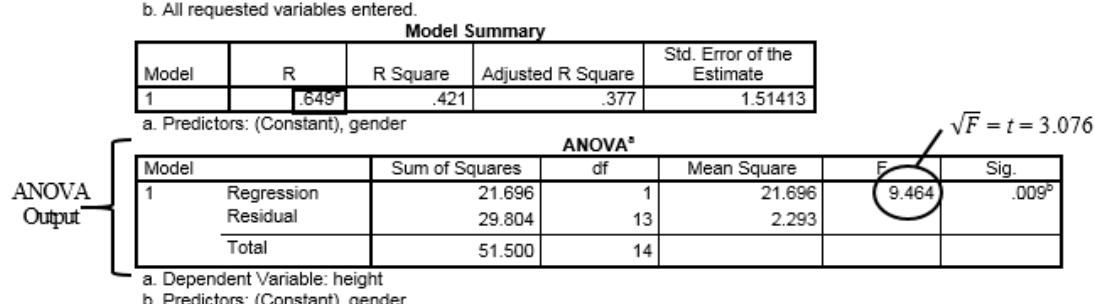

b. Predictors: (Constant), gender

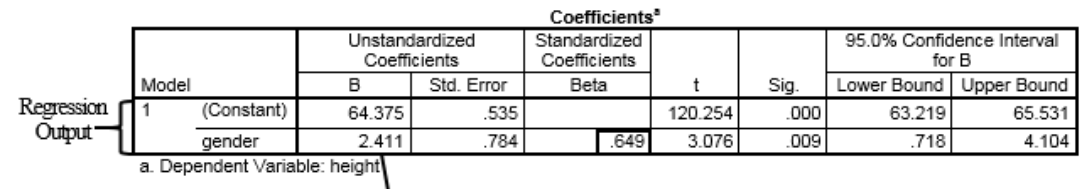

\begin{tabular}{c|r|}
\hline gender & 2.4 \\
\hline a. Dependent Variable: height
\end{tabular}

$64.375+2.411=$
ONTANOVA height BY gender

MOD=SSTYPE (3)

/PRINT=ETASQ HOMOGENEITY DESCRIPTIVE PARAMETER

/CRITERIA $=$ ALPHA $(.05)$

\section{Univariate Analysis of Variance}

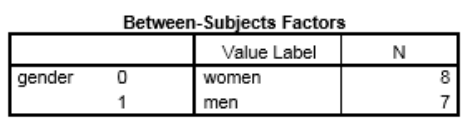

Descriptive Statistics

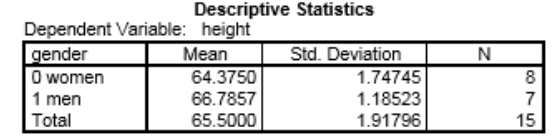

Levene's Test of Equality of Error Variances'

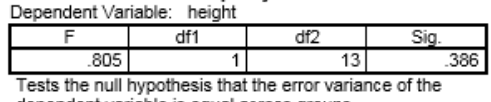

desenthe nuin hypothesis that the error vapan
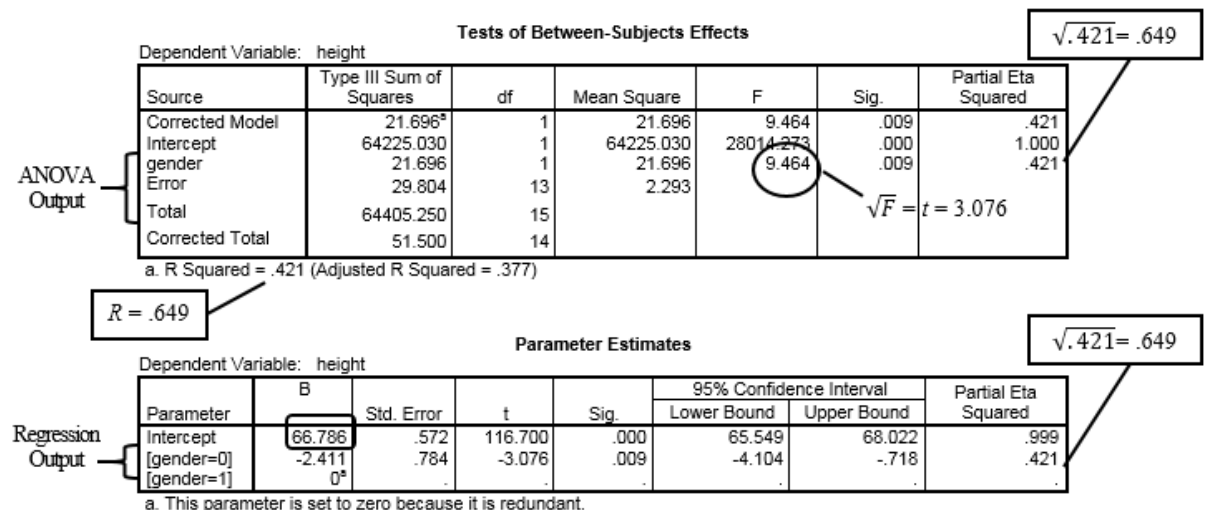

This parameter is set to zero because it is redundant 
provided explicitly. Further, confidence intervals for the mean heights and $r$ are also provided. Perhaps more importantly, the output is explicit and consistent across univariate and multivariate analyses, facilitating students understanding that a general framework undergirds these analyses.

Figure 5. Regression and Univariate General Linear Model Output Comparison in Unimult ${ }^{\mathrm{TM}}$

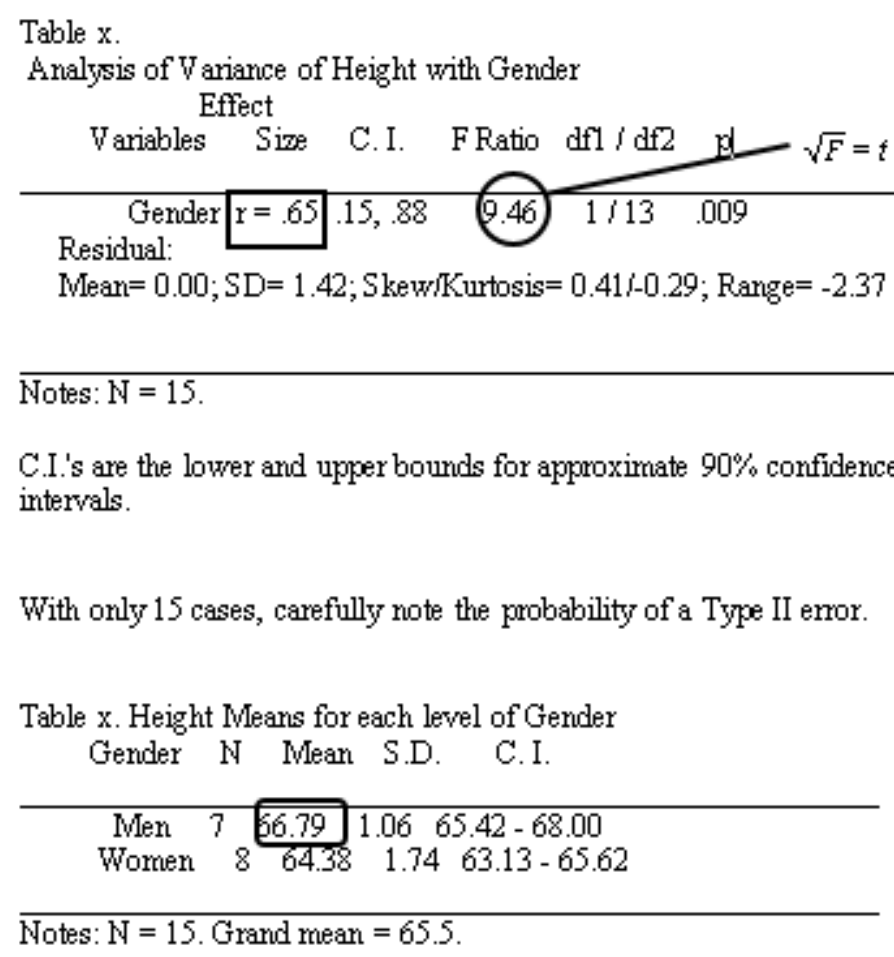

As these examples demonstrate, software developers have begun to incorporate GLM terminology. The commonly used statistical program, SPSS ${ }^{\circledR}$, has incorporated the GLM language, offering users the ability to use GLM options of Univariate, Multivariate, and Repeated Measures. Still, the legacy menu options are available should users wish to use traditional language instead (e.g. Correlate, Regression, $t$-test and ANOVA). The other statistical program discussed, Unimult ${ }^{\mathrm{TM}}$, was "designed and programmed from the first to the last line of code as a GLM processor", and as such, is explicitly focused on the analysis of univariate and multivariate data within the GLM framework. Further, users do not need to know the names of the individual analyses in order to run an analysis. Instead, users simply need to know which are the independent and dependent variables and the measurement scale of each. Regardless of the software used, it is critical that instructors point out the connections 
among analyses subsumed within the GLM. Again, the focus is on the components of the GLM - the weights applied to observed variables that result in a latent variable and the variance accounted for effect sizes that provide an estimate of model fit.

\section{Discussion}

The preceding three examples explain the basic principles within the GLM that can be reiterated across analyses within the GLM; (a) all these analyses apply weights to measured (observed) variables in such a way that error variance is minimized, (b) latent (unobserved) variables result, and (c) variance accounted for effect sizes analogous to $r^{2}$ can be calculated (Thompson, 2006). Instructors who help students recognize standardized and unstandardized weights, observed and latent variables, and variance accounted for effect sizes, equip students with a framework within which to build other analyses upon. A clear understanding of these terms becomes more valuable as students see analogous terms in other GLM analysis. It is helpful if these analogous terms are made explicit. Because traditional approaches, with their respective nomenclature, are prevalent, a GLM term crosswalk, provided in Table 3, is often helpful. For example,

Table 3

Analogous Terms across Four GLM Analyses

\begin{tabular}{llll}
\hline Regression & Factor analysis & $\begin{array}{l}\text { Descriptive } \\
\text { discriminant } \\
\text { analysis }\end{array}$ & $\begin{array}{l}\text { Canonical } \\
\text { correlation } \\
\text { analysis }\end{array}$ \\
\hline Beta weights & Pattern coefficients & $\begin{array}{l}\text { Standardized } \\
\text { canonical } \\
\text { discriminant } \\
\text { function } \\
\text { coefficients }\end{array}$ & $\begin{array}{l}\text { Standardized } \\
\text { canonical } \\
\text { coefficients }\end{array}$ \\
$\begin{array}{l}\text { Structure } \\
\text { coefficients }\end{array}$ & $\begin{array}{l}\text { Structure } \\
\text { coefficients }\end{array}$ & $\begin{array}{l}\text { Structure } \\
\text { matrix }\end{array}$ & $\begin{array}{l}\text { Canonical } \\
\text { structure } \\
\text { coefficients }\end{array}$ \\
Equation & Factor & Function & Function \\
Y-hat & Factor scores & $\begin{array}{l}\text { Discriminant } \\
\text { scores }\end{array}$ & $\begin{array}{l}\text { Canonical } \\
\text { function scores }\end{array}$ \\
$R^{2}$ & & $R_{\mathrm{c}^{2}}$ & $R_{\mathrm{c}^{2}}$ \\
\hline
\end{tabular}


students can begin to understand that $R^{2}$ in regression is analogous to the communality coefficient, $h^{2}$, in factor analysis, and $R_{\mathrm{c}^{2}}$ in descriptive discriminant analysis, and canonical correlation analysis. Moreover, taking a unified approach to understanding statistics can also help students recognize a similar interpretation strategy across the GLM, i.e., Do I have anything? And, Where does my something originate? (cf., Thompson, 2006).

Kirk's (2001) multifaceted approach to promoting sound statistical practices included a call to action from multiple sources such as textbook authors, quantitative instructors, curriculum writers, software developers, journal editors, and authors of publication manuals. Although the focus of the present paper is on teaching, a multifaceted approach is also called for. As has been noted, the statistical training of future psychologist impacts the field. Textbook authors can assist instructors by providing textbooks and resources that focus on the GLM. Software developers can continue to move towards a more integrated approach to statistical analyses within GLM. Journal editors can encourage a more unified approach to analyses instead of clear delineations between a $t$-test and an ANOVA, for example. And authors of publication manuals can emphasize the GLM in their representative tables, figures, and text. Simply because analyses were developed from different disciplines at different times, it is not necessary to continue to treat them as separate entities.

Author notes: An earlier draft of this manuscript, "Teaching GLM Concepts: Explicating the Connections", was presented at the American Psychological Association 2014 Annual Meeting, Washington, D. C.

\section{References}

Aiken, L. S., West, S. G., \& Millsap, R. E. (2009). Improving training in methodology enriches the science of psychology. American Psychologist, 64, 51-52. doi:10.1037/aoo14161

Aiken, L. S., West, S. G., \& Millsap, R. E. (2008). Doctoral training in statistics, measurement and methodology in psychology. American Psychologist, 63, 32-50. doi:10.1037/0003-066X.63.1.32

Aiken, L. S., West, S. G., Sechrest, L., Reno, R. R., Roediger III, H. L., Scarr, S., et al. (1990). Graduate training in statistics, methodology, and measurement in psychology: A survey of $\mathrm{PhD}$ programs in North America. American Psychologist, 45, 721-734. doi:10.1037/0003-066X.45.6.721

Bagozzi, R. P., Fornell, C., \& Larcker, D. F. (1981). Canonical correlation analysis as a special case of a structural relations model. Multivariate Behavioral Research, 16, 437-454. doi:10.1207/s15327906mbr1604_2

Box, G. E. P., \& Draper, N. R. (1987). Empirical model-building and response surfaces. New York: John Wiley \& Sons. 
Chartier, S., \& Faulkner, A. (2008). General linear models: An integrated approach to statistics. Tutorials in Quantitative Methods for Psychology, 4, 65-78.

Fan, X. (1997). Canonical correlation analysis and structural equation modeling: What do they have in common? Structural Equation Modeling: A Multidisciplinary Journal, 4, 65-79. doi:10.1080/10705519709540060

Friedrich, J., \& Buday, E. (2000). Statistical training in psychology: A national survey and commentary on undergraduate programs. Teaching of Psychology, 27, 248-257. doi:10.1207/S15328023TOP2704_02

Gelso, C. J. (2006). On the making of a scientist-practitioner: A theory of research training in professional psychology. Training and Education in Professional Psychology (1), 3-16. doi:10.1037/1931-3918.S.1.3

Gelso, C. J., Baumann, E. C., Chui, H. T., \& Savela, A. E. (2013). The making of a scientist-psychotherapist: The research training environment and the psychotherapist. Psychotherapy, 5o(2), 139-149. doi:10.1037/a0028257

Graham, J. M. (2008). The general linear model as structural equation modeling. Journal of Educational and Behavioral Statistics, 33, 485-506. doi:10.3102/1076998607306151

Kirk, R. E. (2001). Promoting good statistical practices: Some suggestions. Educational and Psychological Measurement, 61, 213-218. doi:10.1177/00131640121971185

Knapp, T. R. (1978). Canonical correlation analysis: A general parametric significance-testing system. Psychological Bulletin, 85, 410-416. doi:10.1037/0033-2909.85.2.410

n.a. (2014). What is a course description? [Website]. Retrieved from https://studentaffairs.stanford.edu/registrar/staff/bulletin-course-descr

Rossen, E., \& Oakland, T. (2008). Graduate preparation in research methods: The current status of APA-accredited professional programs in psychology. Training and Education in Professional Psychology, 2, 42-49. doi:10.1037/1931-3918.2.1.42

Ruebush, L. E., Sulikowski, M. M., \& North, S. W. (2009). A simple exercise changes the way students think about scientific modeling. Journal of College Science Teaching, 38, 24-28.

Ruebush, L. E., Grossman, E. L., Miller, S. A., North, S. W., Schielack, J. F., \& Simanek, E. E. (2010). Scientists' perspective on introducing authentic inquiry to high school teachers during an intensive three-week summer professional development experience. School Science and Mathematics, 109, 162-174. doi:10.1111/j.1949-8594.2009.tb17952.x

Silverman, R. J. (1987). How we know what we know: A study of higher education journal articles. Review of Higher Education, 11, 39-59.

Skidmore, S. T., \& Thompson, B. (2010). Statistical techniques used in published articles: A historical review of reviews. Educational and Psychological Measurement, 70, 777-795. doi:10.1177/0013164410379320

Thompson, B. (1984). Canonical correlation analysis: Uses and interpretation. Beverly Hills: Sage.

Thompson, B. (2006). Foundations of behavioral statistics: An insight-based approach. New York: Guilford. 


\section{TEACHING GLM}

Wickens, T. D. (2004, July). The general linear model. Paper presented at the Mathematics in Brain Imaging Graduate Summer School Program, Los Angeles, CA.

Wilks, S. S. (1951). Undergraduate statistical education. Journal of the American Statistical Association, 46, 1-18. doi:10.1080/01621459.1951.10500763 